\title{
INFLUENCE OF REINFORCED CONCRETE FORMING FEATURES ON MECHANICAL CHARACTERISTICS
}

\author{
Marina DRAPALUK
}

\begin{abstract}
The article found that defects in cement and aggregate grains can not only cause stress concentration and contribute to cracking, but also can stop their propagation It was determined that, in addition to zones with reduced strength, a zone with an increased viscosity can become a brake on the path of a growing crack, having a modulus of elasticity much less than the modulus of elasticity of the base material. The influence of moulding of reinforced concrete structures on its mechanical characteristics was revealed. It can be stated that mineral additives of various nature, regardless of hydraulic activity degree, optimize the deformative properties of cement stone and concrete with practically constant compressive strength.
\end{abstract}

Keywords: cement stone; defects; mineral additives; shrinkage cracks

\section{INTRODUCTION}

The main mechanism that establishes the cracks propagation in concrete on a dense aggregate is the failure of adhesion at the interface of "cement stone - aggregate". These assumptions were confirmed by numerous studies of the interface. This area is usually weaker than the mortar part and is the site of microcrack formation as a result of water separation and shrinkage. On the other hand, the analysis of stresses from an external load showed the presence of places with a high concentration of stresses, which cause the development of initial microcracks in the main separation crack. From this it follows that the interface of the "cement stone - aggregate" is capable of blocking the developing crack only in the event that there is sufficient adhesion of the aggregate to the cement stone. With low adhesive strength, this surface is the area from which cracks develop, which determine the nature of the general destruction of concrete.

\section{ANALYSIS OF RECENT RESEARCH}

The dual role of various defects (pores, initial shrinkage cracks) in cement and aggregate grains was noticed by Popovich [1], highlighting that, first of all, they can cause stress concentration and contribute to the appearance of cracks; secondly, they can suspend their propagation. He noticed that when compressing, pores in the concrete prevent propagation of cracks to a greater extent than when stretching. That is why, in his opinion, increase in porosity will worsen the strength of concrete at compression more than its tensile or bending strength. The role of the aggregate in inhibiting the growth and quenching of brittle cracks is convincingly enough characterized by the data of many researchers, in particular, Sytnik and Ivanov [2], who discovered that the destruction of cement stone occurs suddenly. Parametric levels of cracks formation for it are not observed, i.e. they coincide with the ultimate strength. Ya. Tanigawa and E. Hosaka [3] came to the same conclusion when investigating the cracking of cement stone. They found that the samples break down immediately after propagation of macrocracks along the longitudinal axis because there is no aggregate in the cement stone that stops their propagation. When studying the mechanism of crystalline bodies destruction, Frenkel [4] noted that development and growth of cracks could be effectively inhibited by fine pores present in the material, as well as inclusions with less strength or modulus of elasticity. Consequently, in addition to zones with reduced strength, zones with increased viscosity may become an effective brake in the path of a growing crack, having a modulus of elasticity much less than the modulus of elasticity of the base material. In addition to high viscoplastic properties, said zones should also possess excellent adhesion to the base material.

\section{PURPOSE AND OBJECTIVES}

At present, there are known studies and experience in the use of mineral and organic weakly rigid porous components (additives) of various dispersity in concrete mixtures: from dispersity of binding one to the size of fine and coarse aggregates [5]. It is portland cement with mineral additives and pozzolanic portland cement, mortars and concretes on mixed and combined aggregates. The listed materials are characterized by savings in the clinker part (when using finely dispersed mineral additives), reduced density of concrete with mixed aggregates), increased crack resistance, frost resistance, in some cases - tensile strength [6]. Summarizing the results of studies carried out to date in this field, it is expedient to differentiate such components depending on their dispersion. In accordance with this, it is possible to isolate finely dispersed components (additives) with a specific surface of 50-300 $\mathrm{m}^{2} / \mathrm{kg}$ [6]; components with dimensions of fine aggregate - sand; components with dimensions of coarse aggregate. Therefore, it is important to determine the ways to optimize the structure of concrete in order to increase the crack resistance and durability.

\section{OBJECTS AND METHODS OF RESEARCH}

In case of uniaxial and triaxial compression of ordinary concrete, the initial cracks are formed mainly under the 
grains of coarse aggregate even before loading [7]. It weakens the contact layer, breaks monolithic, reduces the uniformity and strength of concrete as a whole. The weakness of the contact layer is determined by sedimentation processes in freshly laid concrete and the development of shrinkage cracks in it during hardening. First, as a result of internal water separation, water accumulates under the grains of aggregate, resulting in the formation of pores, partially or completely filled with water [7]. During the hardening of concrete, the defectiveness of the contact layer is enhanced by the appearance of shrinkage stresses and, as a consequence, the formation and development of shrinkage cracks localized mainly at the interfaces of phases with different stiffness. At the same time, defects in cement and aggregate grains can, firstly, serve as a cause of stress concentration and contribute to the appearance of cracks; secondly, they can suspend their propagation [7]. It was noted that when compressing the pores in the concrete, the crack propagation is prevented more than by stretching [7].

Mechanism of inhibition of destruction processes of concrete is determined by the presence in it of "weak" elastoviscous and layered inclusions, which reduce local stresses and extinguish energy of cracks growth. Such layered inclusions include hydrosilicates and calcium hydroxide, as well as additives of polymers and expanded vermiculite.

In addition, viscous catalysts for brittle fracture of concrete are closed air pores, which, on the one hand, reduce the effective cross-section of the material, and on the other they are able to redistribute local stresses in concrete among its components with different elasticity.

\section{SCIENTIFIC RESULTS}

As a result of analysis of the degree of technological factors influence on the processes of moulding the operational properties of the concrete being developed, it is established that it is expedient to use dry concrete moulding technology.

However, transporting and placement of a concrete mixture in a mould for a dry concrete mix becomes very important due to delamination during transportation, placement in a mould, and distribution in a mould. The experience of transporting dry mixtures in bags and sealed containers for the factory production of reinforced concrete products is not economically justified [8].

Other technical solutions, with the exception of the proposal to supply the feeder of the concrete paver with a protective casing and equip the loading panel with a reciprocating drive, are not available.

An important technological conversion is solidification. The average density of a dry concrete mixture of different composition was solidified when it was solidified by vibrating, impact method and rolling, the mixtures were solidified layer by layer of different thickness.

The parameters of solidification - amplitude and frequency of oscillations (impacts) were also varied; the intensity of the load and vibration and impact solidification time; speed of movement and linear pressure of the roller with a rolling seal.

Based on the conducted studies, it was concluded that the highest quality of solidification was achieved when the concrete mix was placed with vibrating and loading [9].

The influence of vibration parameters on the workability of modified concrete mixtures of dry moulding of different compositions was determined under the conditions of mixture distribution by shape and vacuuming. For this purpose, several compositions of dry concrete mixtures with a cement content in the mortar part of $C /(C+S)=0.3 ; 0.7$; 1.0 and with the same ratio of the mass of the mortar part to the total mass of the concrete mix $S /(S+L)$. In order to simulate the processes of efflux and compaction of modified concrete dry moulding, a viscometer was used in the mold. Four modes of vibrocompaction were set: frequency $f=50$ $\mathrm{Hz}$, acceleration $A \mathrm{~g}=1.5 \mathrm{~g} ; 2.5 \mathrm{~g} ; 3.5 \mathrm{~g} ; 4.5 \mathrm{~g}$. The results of the experiments are given in Tab. 1.

Table 1 Influence of vibration intensity on the workability of modified concrete mixes of dry molding during vibrating compaction and vibrodistribution their form

\begin{tabular}{|c|c|c|c|c|c|c|c|c|c|c|}
\hline \multirow{3}{*}{$\begin{array}{l}\dot{0} \\
z \\
\text { Z् }\end{array}$} & \multicolumn{2}{|c|}{$\begin{array}{l}\text { The composition } \\
\text { of the mixture }\end{array}$} & \multicolumn{8}{|c|}{$\begin{array}{l}\text { The distribution and compaction time of the } \\
\text { mixture } \tau_{1} \text { and } \tau_{2}, c \text {, during acceleration }\end{array}$} \\
\hline & \multirow{2}{*}{$\frac{C}{C+S}$} & \multirow{2}{*}{$\frac{S}{S+L}$} & \multicolumn{2}{|c|}{$1,5 \mathrm{~g}$} & \multicolumn{2}{|c|}{$2,5 \mathrm{~g}$} & \multicolumn{2}{|c|}{$3,5 \mathrm{~g}$} & \multicolumn{2}{|c|}{$4,5 \mathrm{~g}$} \\
\hline & & & $\tau_{1}$ & $\tau_{2}$ & $\tau_{1}$ & $\tau_{2}$ & $\tau_{1}$ & $\tau_{2}$ & $\tau_{1}$ & $\tau_{2}$ \\
\hline 1 & 0 & 0.3 & 32 & 56 & 24 & 47 & 18 & 30 & 12 & 25 \\
\hline 2 & 0 & 0.7 & 54 & 63 & 35 & 55 & 25 & 35 & 20 & 28 \\
\hline 3 & 0 & 1.0 & 57 & 65 & 35 & 60 & 30 & 36 & 24 & 35 \\
\hline 4 & 0.3 & 0.3 & 52 & 68 & 30 & 37 & 23 & 25 & 18 & 25 \\
\hline 5 & 0.3 & 0.7 & 61 & 77 & 32 & 37 & 25 & 32 & 21 & 27 \\
\hline 6 & 0.3 & 1.0 & 64 & 89 & 40 & 45 & 28 & 40 & 23 & 30 \\
\hline 7 & 0.7 & 0.3 & 55 & 63 & 33 & 47 & 25 & 30 & 20 & 28 \\
\hline 8 & 0.7 & 0.7 & 63 & 81 & 40 & 52 & 30 & 40 & 26 & 40 \\
\hline 9 & 0.7 & 1.0 & 70 & 92 & 49 & 60 & 27 & 43 & 25 & 41 \\
\hline 10 & 1.0 & 0.3 & 60 & 68 & 35 & 60 & 24 & 39 & 20 & 25 \\
\hline 11 & 1.0 & 0.7 & 67 & 79 & 40 & 63 & 28 & 47 & 23 & 40 \\
\hline 12 & 1.0 & 1.0 & 70 & 90 & 47 & 62 & 30 & 46 & 25 & 37 \\
\hline
\end{tabular}

Table 2 Influence of vibration intensity on the workability of modified dry-formed concrete mixes with vibratory vacuum compaction with expiry

\begin{tabular}{|c|c|c|c|c|c|c|c|c|c|c|}
\hline \multirow{3}{*}{ 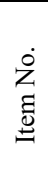 } & \multicolumn{2}{|c|}{$\begin{array}{l}\text { The composition } \\
\text { of the mixture }\end{array}$} & \multicolumn{8}{|c|}{$\begin{array}{l}\text { The distribution and compaction time of } \\
\text { the mixture } \tau_{1} \text { and } \tau_{2}, c \text {, during } \\
\text { acceleration }\end{array}$} \\
\hline & \multirow{2}{*}{$\frac{C}{C+S}$} & \multirow{2}{*}{$\frac{S}{S+L}$} & \multicolumn{2}{|c|}{$1.5 \mathrm{~g}$} & \multicolumn{2}{|c|}{$2.5 \mathrm{~g}$} & \multicolumn{2}{|c|}{$3.5 \mathrm{~g}$} & \multicolumn{2}{|c|}{$4.5 \mathrm{~g}$} \\
\hline & & & $\tau_{1}$ & $\tau_{2}$ & $\tau_{1}$ & $\tau_{2}$ & $\tau_{1}$ & $\tau_{2}$ & $\tau_{1}$ & $\tau_{2}$ \\
\hline $\begin{array}{c}1 \\
2 \\
3 \\
4 \\
5 \\
6 \\
7 \\
8 \\
9 \\
10 \\
11 \\
12\end{array}$ & $\begin{array}{c}0 \\
0 \\
0 \\
0.3 \\
0.3 \\
0.3 \\
0.7 \\
0.7 \\
0.7 \\
1.0 \\
1.0 \\
1.0\end{array}$ & $\begin{array}{l}0.3 \\
0.7 \\
1.0 \\
0.3 \\
0.7 \\
1.0 \\
0.3 \\
0.7 \\
1.0 \\
0.3 \\
0.7 \\
1.0\end{array}$ & $\begin{array}{l}27 \\
46 \\
48 \\
45 \\
49 \\
50 \\
47 \\
50 \\
53 \\
47 \\
47 \\
45\end{array}$ & $\begin{array}{l}5 \\
0 \\
5 \\
3 \\
5 \\
8 \\
5 \\
3 \\
5 \\
6 \\
5 \\
9 \\
6 \\
0 \\
6 \\
7 \\
7 \\
0 \\
6 \\
5 \\
6 \\
5 \\
6 \\
6\end{array}$ & $\begin{array}{l}2 \\
6 \\
2 \\
8 \\
3 \\
0 \\
3 \\
4 \\
2 \\
8 \\
3 \\
5 \\
3 \\
6 \\
3 \\
4 \\
3 \\
9 \\
3 \\
3 \\
3 \\
5 \\
3 \\
6\end{array}$ & $\begin{array}{l}2 \\
5 \\
3 \\
8 \\
4 \\
3 \\
4 \\
7 \\
4 \\
9 \\
4 \\
4 \\
4 \\
9 \\
5 \\
2 \\
5 \\
7 \\
5 \\
1 \\
5 \\
4 \\
5 \\
3\end{array}$ & $\begin{array}{l}1 \\
6 \\
2 \\
0 \\
2 \\
2 \\
2 \\
0 \\
2 \\
0 \\
1 \\
8 \\
2 \\
1 \\
2 \\
3 \\
1 \\
9 \\
2 \\
0 \\
2 \\
2 \\
1 \\
6\end{array}$ & $\begin{array}{l}2 \\
9 \\
3 \\
2 \\
7 \\
2 \\
5 \\
3 \\
0 \\
3 \\
3 \\
4 \\
0 \\
4 \\
0\end{array}$ & $\begin{array}{l}1 \\
0 \\
1 \\
6 \\
2 \\
1 \\
1 \\
8 \\
1 \\
7 \\
1 \\
8 \\
1 \\
9 \\
2 \\
0 \\
2 \\
0 \\
1 \\
8 \\
1 \\
9\end{array}$ & $\begin{array}{l}2 \\
3 \\
3 \\
0 \\
2 \\
9 \\
2 \\
5 \\
2 \\
4 \\
2 \\
5 \\
2 \\
4 \\
2 \\
3 \\
2 \\
1 \\
2 \\
5 \\
2 \\
8 \\
3 \\
2\end{array}$ \\
\hline
\end{tabular}


As can be seen in Tab. 1, as the amount of sand and cement in the mixture increases, the hardness $\tau_{1}$ increases from 32 to 57 and $70 \mathrm{~s}$ with an acceleration of $1.5 \mathrm{~g}$, and from 12 to 24 and $25 \mathrm{~s}$ with an acceleration of $4.5 \mathrm{~g}$. The time for reaching the maximum density $\tau_{2}$ also increases. The data Tab. 1 allows us to predict the rigidity and assign the time of vibrocompaction of modified concrete mixes of dry moulding, depending on the composition of the mixture and the intensity of vibration, but this is for normal moulding conditions.

To determine the rational modes of vibrovacuum moulding, the experiment was repeated with a vacuum of
$0.09 \mathrm{MPa}$ on the same mixing gauge, but with the vacuumbag installed. The results of the experiment are given in Tab. 2.

From the comparison of Tabs. 1 and 2, it is evident that vacuuming reduces the time of distribution and compaction of modified dry-formed concrete mixes with a high content of sand and cement by about $20 \%$.

Methods of water saturation of the concrete mixture, in particular, the condensation of water vapour, are also important. At the same time, the process is carried out either independently of other technological processes, or in the process of heat and moisture treatment (Tab. 3).

Table 3 Influence of impregnation methods and modes on the wetting rate of a dry sample (cylinder diameter and height $15 \mathrm{~cm}$ )

\begin{tabular}{|c|c|c|}
\hline Impregnation method & Impregnation mode & $\begin{array}{l}\text { Duration of impregnation, } \\
\text { min }\end{array}$ \\
\hline Capillary suction & $\begin{array}{l}\text { Immersion in water at a temperature of } 20^{\circ} \mathrm{C} \\
\text { The same, } 2 \% \text { solution of PFM-BS } \\
\text { The same, } 2 \% \text { fleeceflower extract solution } \\
\text { The same, in liquid glass, } \rho=1.2 \mathrm{~kg} / \mathrm{dm}^{3} \\
\text { The same, hot water } 80^{\circ} \mathrm{C}\end{array}$ & $\begin{array}{c}328 \\
275 \\
294 \\
\text { more than } 12 \mathrm{~h} \\
275\end{array}$ \\
\hline Pressure filtration & $\begin{array}{l}\text { One-sided water injection at a pressure of } 0.05 \mathrm{MPa} \\
\text { The same, } 2 \% \text { solution of PFM-BS } \\
\text { The same, } 2 \% \text { fleeceflower extract solution } \\
\text { The same, hot water } 80^{\circ} \mathrm{C} \\
\text { Single-side suction of water with a vacuum of } 0.005 \mathrm{MPa} \\
\text { The same, of water at } 80^{\circ} \mathrm{C} \\
\text { Injection of liquid glass } \rho=1.2 \mathrm{~kg} / \mathrm{dm}^{3} \text { with a pressure of } 0.1 \mathrm{MPa} \\
\text { Suction of liquid glass } \rho=1.2 \mathrm{~kg} / \mathrm{dm}^{3} \text { with a pressure of } 0.1 \mathrm{MPa} \\
\text { Suction-injection of liquid glass } \rho=1.2 \mathrm{~kg} / \mathrm{dm}^{3} \text { with a pressure of } 0.1 \mathrm{MPa} \text { and a vacuum of } 0.1 \\
\text { MPa } \\
\text { The same at } 80^{\circ} \mathrm{C}\end{array}$ & $\begin{array}{c}\text { Channel formation } \\
54 \\
77 \\
62 \\
4.0 \\
2.4 \\
124 \\
27 \\
5.0 \\
3.5\end{array}$ \\
\hline Condensation & $\begin{array}{l}\text { Volumetric steam injection with a pressure of } 0.1 \mathrm{MPa} \\
\text { Volumetric suction of steam with a pressure of } 0.1 \mathrm{MPa} \\
\text { Injection of steam with a pressure of } 0.1 \mathrm{MPa} \text { into the previously evacuated dry mixture }\end{array}$ & $\begin{array}{c}63 \\
2.0 \\
\text { less than } 2 \mathrm{~min} \\
\end{array}$ \\
\hline
\end{tabular}

Saturation of a dry concrete mixture with steam condensate in the process of heat and moisture treatment leads to the wetting of the surface of the layer of all the product facets, in connection with it, the air in the volume of the mixture is entrapped, and the saturation of the product is extremely difficult. For a more complete impregnation, it is also suggested to apply hot water to the surface of the product after steam is applied and a "crust" is formed, and then again steam. However, it does not change the mechanism of air entrapment in the volume of the product and, moreover, has limited application. It is also proposed to use steam for the water saturation in the process of heat and moisture treatment with a pressure of $0.5 \mathrm{MPa}$.

It reduces the impregnation time to 3-13.5 min. However, in this case, the effect of air entrapment in the volume is preserved, and complete moistening of the sample is not guaranteed. It is also possible to carry out water saturation under pressure, which, depending on the thickness of the product, should be from 0.2 to $0.6 \mathrm{MPa}$ ( 0.2 for a 10 cm layer, 0.6 for a $40 \mathrm{~cm}$ layer).

Preference is given to the use of hot water, since with increasing temperature its dynamic viscosity decreases. When the pressure is increased from 0.1 to $1.0 \mathrm{MPa}$, the saturation time of the layer of the concrete mixture $10 \mathrm{~cm}$ thick is reduced from 28 to 2.8 minutes. For a layer of $30 \mathrm{~cm}$, the saturation time of the sample at a pressure of $0.3 \mathrm{MPa}$ is 46 minutes. Thus, the most effective way of water saturation is water saturation at a pressure of 0.3-0.5 MPa. However, there is a danger of washing through channels in a disconnected semidry mixture. For real products, where local inhomogeneities are unavoidable due to large sizes (in the density of the dry mix, in the density of the filtering elements, etc.), this method is not possible. Another important issue is selection of the dry-formed concrete composition. When calculating the composition of water-based mixtures, they are first set by the flow of water, which then allows the calculation of the amount of cement. With dry moulding, the water flow cannot be set, since it is a function of the density of the mixture, and density is a function of the consumption of cement, sand, gravel. Therefore, the absolute volume method for dry mixtures is unacceptable.

At present, there are three main methods for designing dry concrete composition. Gusev et al. [10] suggest starting the calculation with the choice of an astringent whose activity should correspond to the brand of concrete. Calculation is based on the dependence of the strength (grade) of concrete on the packing density of solid-phase components. To find the optimal ratio of components, it is proposed to make mixtures of components and to determine experimentally the optimum ratio of components [10]. The authors do not give acceptable formulas for the calculation.

The empirical dependence of the strength of dry-formed concrete on the packing density of solid-phase components [11] is also based on the calculation proposed by 
Ovchinnikov.

The method of designing the composition of dry concrete is most fully described in [11]. According to this method, the average density is first assigned, depending on the type of construction and the method of solidification. Then, according to the known strength and average density, the required binder activity is determined. Finally, from the experimental graphs, water demand and cement consumption are determined, and then the aggregate consumption and the proportion of sand in it are calculated. However, this method does not provide for taking into account the specific properties of the components and, in addition, it assumes the possibility of a free choice of the cement brand, which is impracticable.

In connection with the above, we have proposed a method for assigning a dry concrete mix, based on the following theoretical considerations.

1) The strength of concrete depends on the water-cement ratio, and the water-cement ratio in dry concrete is directly determined by the ratio of cement and sand. As the cement is saturated with voids in the sand, the voidness of the solution, and therefore, the water-cement ratio decreases. After filling with a volume of voids in the sand, the cement becomes densified with a further decrease in voidness and watercement ratio. When the cement packing density reaches its maximum value, a further increase in its consumption leads to a proportional increase in the volume of intergranular voids. The porosity and the subsequent water content increase, while in the water-cement ratio it remains constant.

2) At a given ratio of cement and sand, the minimum cement consumption will be in the case where the packing density of solid phase components is maximum.

To check this reasoning, a series of experiments was carried out, the purpose of which was to establish a quantitative relationship between the cement fraction in the solution mixture $C /(C+S)$, the water-cement ratio, and the strength of the concrete. The results are shown in Tab. 4, from which it follows that as the cement content increases, the density of the mixture first increases sharply with a maximum at $C=500 \mathrm{~kg} / \mathrm{m}^{3}$, and then decreases. The strength first increases sharply from 30 to $70 \mathrm{MPa}$ and stabilizes at water-cement ratio $=0.27-0.25$ (Tab. 4).

Table 4 Dependence of the water-cement ratio and strength on the cement content in the solution component of concrete

\begin{tabular}{|c|c|c|c|c|c|c|}
\hline Item & \multicolumn{3}{|c|}{ Initial data } & \multicolumn{3}{c|}{ Comparable data } \\
\cline { 2 - 7 } No. & $C, \mathrm{~kg} / \mathrm{m}^{3}$ & $S, \mathrm{~kg} / \mathrm{m}^{3}$ & $K_{\mathrm{u}}$ & $C /(C+S)$ & $W / C$ & $f_{\text {cc }}, \mathrm{MPa}$ \\
\hline 1 & 300 & 975 & 0.814 & 0.239 & 0.62 & 39.8 \\
\hline 2 & 400 & 880 & 0.844 & 0.312 & 0.39 & 53.8 \\
\hline 3 & 500 & 775 & 0.854 & 0.408 & 0.292 & 69.2 \\
\hline 4 & 550 & 710 & 0.854 & 0.436 & 0.265 & 79.3 \\
\hline 5 & 600 & 600 & 0.846 & 0.500 & 0.256 & 81.2 \\
\hline
\end{tabular}

Remark: $R_{\mathrm{c}}=43 \mathrm{MPa}$.

Thus, the correlation between $C /(C+S)$ and water-cement ratio, and therefore between $C /(C+S)$ and $R_{\mathrm{b}}$, is expressed quite clearly, and the task is only to quantify this relationship for the conditions of use of different materials. To solve this problem, another series of experiments was carried out on three different types of cements, two types of sands and two types of crushed stone. Firstly, the densest compositions with different contents of cement were selected for this, a cementsand mixture with a different sand-cement ratio was prepared. Then, crushed stone was added in portions to the resulting mixture, and after adding each portion, the mixture was solidified, the average density was determined. The amount of crushed stone, at which the mixture with a given $C / S$ ratio acquired the maximum density, was considered optimal. Cylinders with a diameter and height of $15 \mathrm{~cm}$ were formed from this mixture. The samples were saturated with water at a temperature of $80^{\circ} \mathrm{C}$. After thermo-axial aging for 4-6 $\mathrm{h}$, the samples were lifted and placed in a normal hardening chamber for 28 days. The solidification was produced by vibration with a frequency of $50 \mathrm{~Hz}$ and an acceleration of $3.0 \mathrm{~g}$, the value of the load was $0.09 \mathrm{MPa}$, and the depth of vacuum was $0.09 \mathrm{MPa}$. The moulding mode is taken from Tab. 4. In the results of the determination of the samples strength, it follows that the strength of the dryformed concrete increases with an increase in the $C / S$ ratio, and after a certain $C / S$ ratio, the value of which depends on the sand porosity, the strength increase sharply slows down. This is due to the fact that initially the packing density of the cement particles in the intervals between the grains of sand increases with $C / S$ ration rising, and porosity of dry and water content of the saturated concrete decrease. After reaching the maximum packing density of cement grains approximately $1700-1800 \mathrm{~kg} / \mathrm{m}^{3}$, further increase in cement consumption is accompanied by a corresponding increase in the amount of water. The water-cement ratio remains constant, which is confirmed by the results of the experiments and the calculation given in Tab. 4. It has also been found that the more porosity there is, the faster its maximum density is achieved with a larger cement content, and the more porosity of crushed rock there is, the more cement-sand mixture is required to achieve the maximum density and strength of concrete.

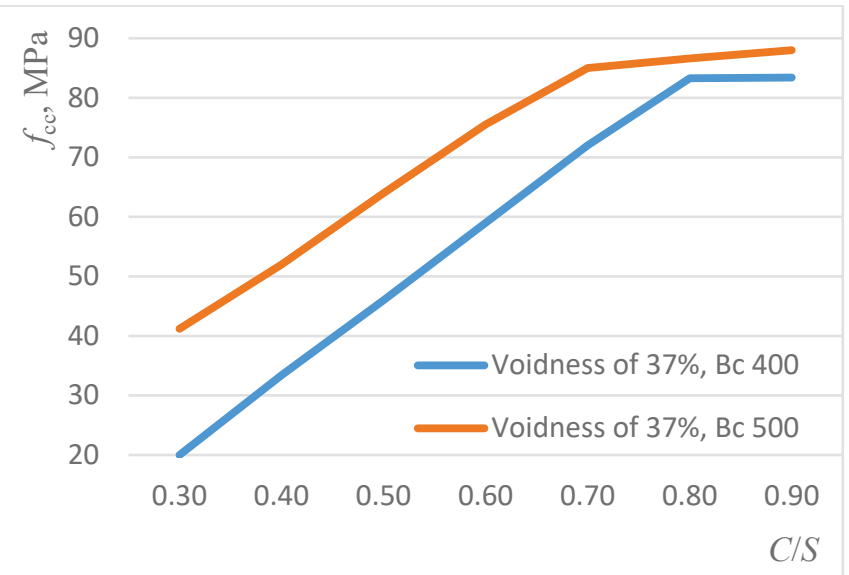

Figure 1 Nomogram for the purpose of cement-sand ratio of dry-formed concrete (with increasing (decreasing) of sand porosity by $1 \%, C / S$ ratio increases (decreases) by 0.01 ).

In accordance with the above provisions, the following procedures for the designation of dry concrete are proposed.

1) From the graph in Fig. 1 the required $C / S$ ratio depending on the given brand of concrete $R_{\mathrm{b}}$, cement activity 
$R_{\mathrm{c}}$ and sand porosity $S_{\mathrm{p}}$ can be found.

2) A dry mixture of cement and sand should be prepared in a predetermined ratio and this mixture should be saturated with crushed stone until the maximum density is achieved.

3) For the maximum average density and the ratio of dry components, their consumption per $1 \mathrm{~m}^{3}$ of concrete is found.

4) Concrete samples are to be prepared and tested, and if their strength is more than $10 \%$ of the required one, the resulting strength value is to be marked on the vertical line corresponding to the found $C / S$ ratio, a line parallel is to be drawn to the strength lines until it meets the required concrete strength and a new value of $C / S$ ratio is to be found. The proposed method favourably differs from the known ones in that it takes into account the properties of specific materials and the conditions for manufacturing the samples. For the design of the composition by this method, it is not necessary to determine the properties of materials, it is only necessary to know the activity of cement (Fig. 1).

It has been found that with dry moulding, the traditional way of lubricating forms with water-emulsion compounds is not always acceptable. When placing a dry mixture in a lubricated mould, the lubricant film partially passes from the mould to the mixture, moulding spots on the finished product. In order to solve the problem in a complex way, a material was chosen for moulds that had zero adhesion to the concrete and did not need lubrication. The technique consisted in determining the strength of the adhesion of concrete to a plate of this material, concreted in the neck of the figure-eight. The results of testing the samples for axial tension are shown in Tab. 5 .

Table 5 Adhesion of dry concrete with various materials (impregnation with a liquid glass solution with a density of $1.2 \mathrm{~kg} / \mathrm{dm}^{3}$ )

\begin{tabular}{|l|c|c|c|c|}
\hline \multirow{2}{*}{\multicolumn{1}{|c|}{ Material }} & \multicolumn{4}{|c|}{$R_{\mathrm{ad}}, \mathrm{MPa}$, at the age, days } \\
\cline { 2 - 5 } & 7 & 14 & 28 & $\begin{array}{c}\text { After SVS } \\
80^{\circ} \mathrm{C}\end{array}$ \\
\hline Stone (granite) & 1.15 & 2.0 & 4.31 & 3.48 \\
\hline Epoxy resin ED-20 & 0.11 & 0.24 & 0.47 & 0.81 \\
\hline Wood (pine) & 0.82 & 1.56 & 3.92 & 3.33 \\
\hline Carbon steel St3sp & 0.65 & 1.34 & 3.00 & 3.05 \\
\hline Stainless steel 14G2 & 0.28 & 0.42 & 0.75 & 0.87 \\
\hline Rubber & 0.15 & 0.25 & 0.62 & 0.77 \\
\hline Polyethylene (film) & 0.00 & 0.00 & 0.00 & 0.09 \\
\hline Polyvinyl chloride (film) & 0.10 & 0.2 & 0.5 & 0.82 \\
\hline
\end{tabular}

It has been established by trials that the optimal material for moulds is polyethylene. Samples with a liner from it were spontaneously separated during excavation from moulds, so the preparation of the formwork for dry moulding consisted of pasting the mould with a polyethylene film. A film with a thickness of $0.3 \mathrm{~mm}$ and a waterproofing enamel consisting of a solution of chlorosulfonated polyethylene in toluene with the addition of a stabilizer was used. Before coating, the moulds were cleaned with a sandblaster, then the enamel layer was applied with a brush. The same layer of enamel was applied to one side of the film and after 30-40 minutes the film was stuck to the surface of the mould.

The technology of manufacturing moulds and matrices with polyethylene coating was proposed in [12].

Introduction of additives into the concrete, which reduce concentration of stresses at the interface with different elastic characteristics, significantly reduces the swing range and limits of changes in the maximum and minimum deformation and stresses during the destruction of concrete. The presence of elastic-viscous inclusions in the structure of the concrete low-modulus additives as internal stress relaxers and energy absorbers of cracks - provides an increase in the strength, fracture toughness and frost resistance of concrete.

It was noted that "heterogeneity of concrete, creating the appearance of microcracks, delays their degeneration into dangerous macrocracks, and presence of stress concentrators in the material structure makes it insensitive to both external concentrators and to newly emerged internal ones." It can be stated that mineral additives of various nature, regardless of the hydraulic activity degree, optimize the deformative properties of cement stone and concrete with practically constant compressive strength. This is due to the reduced rigidity of mineral additives. This additive, in its function, performs in the concrete the role of closed air pores, the effectiveness of which is determined by the theoretical considerations discussed above about the ability of a "weak" surface to energetically quench the growth of a fragile crack.

\section{CONCLUSIONS AND PROSPECTS FOR FURTHER RESEARCH}

Based on the general principles governing the structural and mechanical heterogeneity of the concrete cement matrix, the positive effect of the dry moulding method with slightly hard additives on the structure of concrete and its physical and mechanical characteristics is determined by three factors: at the stage of structure formation, reduction of shrinkage stresses, including the most dangerous tear stresses at the "aggregate-cement matrix" boundary and tensile stresses in the cement matrix; when loaded, frozen and thawed - by equalizing the stresses in the concrete structure and redistributing them among the concrete components with a different modulus of elasticity; inhibition of growth and cracking. It was also established that the reduction of the modulus of elasticity of the aggregate should be within the elasticity modulus of the cement matrix, since a significant decrease in the rigidity of the aggregate will lead to an overload of the cement component and a loss of strength when compressing concrete.

Manifestation of a factor that determines the mechanism of damping cement matrix and concrete largely depends on two parameters of the damping component: its stiffness (modulus of elasticity) and size (dispersion).

1) Reduction of the concrete aggregates hardness due to the use of dense aggregates of medium hardness (such as limestone crushed stone) and light aggregates (slag pumice, expanded clay).

2) Reducing the concentration of dense aggregates due to the expansion of the grains of a large aggregate by cementsand mortar and small one by cement stone.

3) Increasing the aggregate adhesion strength to the cement stone by increasing the purity and the dense aggregates surface roughness, as well as the use of porous aggregates.

4) The use of concretes on mixed coarse and fine 
aggregates, as well as combined concrete, as binder, which uses portland cement with mineral additives, slag portlandcement, pozzolanic and other types of mixed cements.

\section{REFERENCES}

[1] Popovics, S. (1989). Fracture Mechanism in Concrete: How Much Do We Know? J. Eng. Mech. Div. Proc. Amer. Soc. Eng., 95(3), 531-544. (Russian).

[2] Sytnik, V. I. \& Ivanov, Yu. A. (1989). Investigation of micro crack formation in high-strength concretes. Stroitelnye konstruktsii: Respmezhved. nauch.-tekhn. sb. NII stroitelnykh konstruktsiy, Kiev, 12, 42-48 (Russian).

[3] Tanigawa, Ya. \& Hosaka, Ye. (1987). Mekhanizm razvitiya treshchin $i$ razrusheniya betona kak kompozitsionnogo materiala, 90 p. (VTsP No. 89/70795)(Translation from English).

[4] Frenkel, Ya. I. (1968). Staticheskaya fizika. Izd. AN SSSR, 760 p. (English).

[5] Batyanovskiy, E. I. (1982). Effektivnost primeneniya sukhikh betonnykh smesey. Promyshlennoe stroitelstvo i inzhenernye sooruzheniya, 6, 27-32. (Russian).

[6] Taiji, S., Suenory, A., Shigehisa, T., \& Mikio, N. (1980). Effect of Coars Aggregate and Mortal Matrix of the Impact Compressive Strength of Concrete. Rev. $34^{\text {th }}$ Gen. Meet. Cem. Ass. Jap. Techn. Sess., Tokyo, 147-149. (Japanese).

[7] Holland, T. C. (1998). High-Performance Concrete: As High as It Gets. The Concrete Producer, 16(7), 501-505.

[8] Bataynowski, E. I. (1982). Efektiwnost primenenia suhih betonnuch smesey. Promuchlennoe stroitelstwo i ingenernue soorujenia, 6, 27-32. (Russian).

[9] Drapaluk, M. V. (2009). Technologia betona polusuhogo formovania dla elementow gidrotechnicheskih soorugeniy. Westnik Dnipropetrowskogo nacionalnogo uniwersitetu zaliznuchnogo transportu imeni akademika V. Lazarana, 27, 178-180. (Ukrainian).

[10] Gusew, B. V., Deminov, A. D., \& Krukov, B. I. (1982). Udarno-wibracionnaj technologia uplotnenia betonnuh smesey. Stroyizdat, 150 p. (Russian).

[11] Owchinnikow, P. F. (1983). Vibroreologia, Kiev: Naukova dumka, p. 270. (Russian).

[12] Prozorow, A. S., Goldman, F. A., \& Karimov, P. D. (1994). Ispolzowanie form s polimernum pokrutiem dla poluchenia konstrukcii s relefnoy poverchnostu. Beton i zhelezobeton, 5, 11-13.

\section{Author's contact:}

Marina DRAPALUK, Ass. Prof., PhD

Odessa State Academy of Civil Engineering and Architecture,

Didrikhsona St., 465029 Odessa, Ukraine

Tel.: +380 990474585

E-mail: drapalukmarina@meta.ua 